\title{
Serum IL-6 correlates with axial mobility index (Bath Ankylosing Spondylitis Metrology Index) in Brazilian patients with ankylosing spondylitis
}

This article was published in the following Dove Press journal: Open Access Rheumatology: Research and Reviews

\author{
Cristina F Rabelo' \\ Talita Siara Almeida \\ Baptista ${ }^{2}$ \\ Laura Esteves Petersen ${ }^{2}$ \\ Moisés Evandro Bauer ${ }^{2}$ \\ Mauro Waldemar \\ Keiserman' \\ Henrique Luiz Staub' \\ 'Department of Rheumatology, \\ ${ }^{2}$ Laboratory of Immunosenescence, \\ Institute of Biomedical Research, \\ Pontifical Catholic University of Rio \\ Grande do Sul (PUCRS), Porto Alegre, \\ Brazil
}

Introduction: Ankylosing spondylitis (AS) is a chronic disease featuring axial changes, peripheral arthritis and systemic involvement. Proinflammatory cytokines are probably involved in AS pathogenesis. The relationship of circulating cytokines with instruments of AS evaluation is an open field of research.

Objective: The aim of this study was to compare serum levels of cytokines in AS patients and healthy controls, and search for correlations of cytokines with indexes of disease activity and quality of life.

Patients and methods: In this cross-sectional study, 32 AS patients and 32 age- and sexmatched controls were evaluated. Bath Ankylosing Spondylitis Disease Activity Index (BASDAI), Bath Ankylosing Spondylitis Funcional Index (BASFI), Bath Ankylosing Spondylitis Metrology Index (BASMI), Ankylosing Spondylitis Disease Activity Score-C reactive protein (ASDASCRP), Maastricht Ankylosing Spondylitis Enthesitis Score (MASES), Ankylosing Spondylitis Quality of Life (ASQol) and Patient Global Assessment score were measured in AS patients. . The soluble cytokines IL-6, IL-8, IL-1, IL-10, TNF- $\alpha$, IL-12p70 and IL-17 were quantified by flow cytometry. IL-23 concentrations were measured using an enzyme-linked immunosorbent assay. Results: Overall, AS patients were predominantly males $(59.4 \%)$ and Caucasians $(96.9 \%)$. Mean age was $46.9 \pm 10.7$ years. Human leukocyte antigen B27 was present in $70 \%$ of cases. Concentrations of IL-6, IL- 8 , IL-10 and TNF- $\alpha$ were higher in AS cases than controls $(p<0.05)$. Mean concentration of IL- 6 correlated with the BASMI, an index of axial mobility $(r=0.354$, $p=0.047$ ). Anti-TNF intake (present in 21 patients, 65.6\%) associated with a high BASMI $(p=0.042)$ and lower quality of life as measured using the ASQol scale $(p=0.009)$.

Conclusion: A proinflammatory cytokine profile predominated in AS patients, but interestingly, the IL-10 concentrations were also elevated, pointing to a suppressive control of inflammation. A defined correlation of serum IL-6 with the BASMI suggests a role for this cytokine in axial disease. Anti-TNF users showed more axial activity and lower quality of life.

Keywords: ankylosing spondylitis, cytokines, disease activity index, quality-of-life score, BASMI

\section{Introduction}

Ankylosing spondylitis (AS) is a chronic, polygenic inflammatory disorder featuring sacroiliitis and damage of axial skeleton. Peripheral arthritis, enthesopathy and anterior uveitis are common. AS is strongly associated with the human leukocyte antigen HLA-B27, but the pathogenic role of HLA-B27 in AS is yet nebulous. ${ }^{1}$

Recent genome-wide association studies suggested that specific cytokine pathways are involved in AS pathogenesis. Proinflammatory cytokines are probably involved in initiation and perpetuation of disease. For instance, overexpression of IL-17/IL-23 and
Correspondence: Cristina F Rabelo Department of Rheumatology, Saint Lucas Hospital of PUCRS, Avenida Ipiranga 6690, Room 220, 90610-000 Porto Alegre, RS, Brazil Email reumatoacademico@gmail.com 
defective control of nuclear factor kappa B activation have been well demonstrated. ${ }^{2}$

The linkage of cytokine profiles with instruments of clinical evaluation in AS has been an issue of recent interest, with conflicting results. One can hypothesize that particular groups of cytokines might correlate with one or more disease indexes. We herein aimed to compare concentrations of proand anti-inflammatory cytokines in AS Brazilian patients and healthy controls. We also searched for correlations of serum cytokines with instruments of clinical appraisal, including indexes of disease activity and quality of life.

\section{Patients and methods}

In this cross-sectional study, consecutive patients with AS were recruited from our outpatient clinic. Patients above 18 years of age were classified as having AS according to the modified New York ${ }^{3}$ and/or Assessment of SpondyloArthritis international Society (ASAS) criteria for axial disease. ${ }^{4}$ Only patients with symmetrical sacroiliitis were included. Patients were not separated by medication status (regular therapy with anti-inflammatories, immunosuppressants or biologics was maintained in each of them). Subjects with psoriasis, inflammatory bowel disease, reactive arthritis, cancer and acute infectious disease were excluded. Healthy controls matched for age and sex were recruited from our serum bank. This study was approved by the Pontifical Catholic University Committee for Ethics and Research. The patients and control group provided free written informed consent.

The following clinical instruments were utilized to evaluate AS patients: Bath Ankylosing Spondylitis Disease Activity Index (BASDAI); ${ }^{5}$ Bath Ankylosing Spondylitis Functional Index (BASFI); ${ }^{6}$ Bath Ankylosing Spondylitis Metrology Index (BASMI), where five clinical measures evaluate the status of axial skeleton: cervical rotation, tragus-to-wall distance, lumbar side flexion, lumbar flexion and intermalleolar distance; ${ }^{7}$ Ankylosing Spondylitis Disease Activity Score-C reactive protein (ASDAS-CRP) ${ }^{8}$ Maastricht Ankylosing Spondylitis Enthesitis Score (MASES); ${ }^{9}$ Ankylosing Spondylitis Quality of Life (ASQol); ${ }^{10}$ and Patient Global Assessment (PGA) score, taken from the ASDAS.

The soluble cytokines IL-6, IL-8, IL-1, IL-10, TNF- $\alpha$, IL-12p70 and IL-17 were simultaneously measured by flow cytometry using the cytometric bead array Human Inflammatory Cytokine Kit (BD Biosciences, San Jose, CA, USA). The IL-23 concentration was evaluated using an enzyme-linked immunosorbent assay (Thermo Fisher Scientific, Waltham, MA, USA). Results were expressed in pg/mL. CRP levels were searched by dry chemistry method (abnormal above $1 \mathrm{mg} / \mathrm{dL}$ ).
Statistical analyses were performed using SPSS for Windows, version 20.0. Categorical variables were described as numbers and percentage. Variables with a normal distribution were presented as mean \pm standard deviation (SD), and the between-group comparisons were performed using Student's $t$-test. Non-normal quantitative or ordinal variables were presented as the median and interquartile range (representing the values of the 25 th and 75 th percentiles), and the betweengroup comparisons were performed using the Mann-Whitney or Kruskal-Wallis tests. Correlation was assessed using the Spearman or Pearson test. Two-tailed $p$ values equal to or less than 0.05 were considered statistically significant.

\section{Results}

Thirty-two patients and controls comprised our sample, with the mean age being $46.9 \pm 10.7$ years in cases and $46.5 \pm 9.7$ years in controls. Males predominated in cases and controls (19 individuals in each group, 59.4\%). AS was found to be predominant in Caucasians (31 patients, 96.9\%). The median of disease duration was 18 years.

Among the 32 AS patients, 30 fulfilled the modified New York criteria, while the remaining two fulfilled the ASAS criteria for non-radiographic axial spondylitis (nr-axial SpA). Enthesitis was documented in 27 patients (84.5\%), while peripheral arthritis was seen in about $9 \%$ of our patients. Positivity for HLA-B27 was documented in two-third of AS patients (Table 1).

Regarding the BASDAI, elevated values were seen in half of the patients. The medians of BASFI and BASMI were compatible with low-to-moderate disease activity. In turn, an abnormal ASDAS-CRP was seen in all patients. For a maximum score of 13 , the median of MASES (4.5) was compatible with a high frequency of enthesitis. The medians of ASQol and PGA revealed a moderate quality of life.

Regarding drug intake, 21 patients $(65.6 \%)$ were using an anti-TNF- $\alpha$ agent, with a median of $3(2-5)$ years of use. Twelve patients $(37.5 \%)$ were on nonsteroidal anti-inflammatory drugs, and nine $(28.1 \%)$ were on prednisone. Ten patients $(31.3 \%)$ were using methotrexate, and four $(12.5 \%)$ were on sulfasalazine.

The cytokine concentrations of AS patients and controls are shown in Table 2. The IL-6, TNF- $\alpha$, IL-10 and IL-8 concentrations were significantly higher in individuals with AS. Concentrations of IL-12p70, IL-1, IL-23 and IL-17 did not differ between groups.

The correlations of cytokine concentrations with the several instruments of clinical evaluation can be seen in Table 3 . 
Table I Clinical characteristics of the 32 patients with AS

\begin{tabular}{ll}
\hline Variables & Value \\
\hline Age (years; mean \pm standard deviation) & $46.9 \pm 10.7$ \\
Males & $19(59.4 \%)$ \\
White race & $31(96.9 \%)$ \\
Median of disease duration (P25-P75) & $18(10-31)$ \\
Axial spondylitis & \\
Modified New York criteria & $30(93.7 \%)$ \\
ASAS criteria & $2(6.3 \%)$ \\
Enthesitis & $27(84.5 \%)$ \\
Peripheral arthritis & $3(9.4 \%)$ \\
HLA-B27 positivity & $17 / 24(70.8 \%)$ \\
BASDAI (median, P25-P75) & $3.9(2.1-6.3)$ \\
BASDAI elevated ( $\geq 4)$ & $16(50 \%)$ \\
BASFI (median, P25-P75) & $4(1.3-6.0)$ \\
BASMI (median, P25-P75) & $3.4(2.3-4.2)$ \\
ASDAS-CRP (median, P25-P75) & $2.9(2.3-3.5)$ \\
ASDAS-CRP & \\
Inactive disease (<I.3) & $0 / 30(0 \%)$ \\
Moderate activity (I.3-2.I) & $6 / 30(20 \%)$ \\
High activity (2.I-3.4) & $15 / 30(50 \%)$ \\
Very high activity ( $\geq 3.5)$ & $9 / 30(30 \%)$ \\
MASES (median of painful points, P25-P75) & $4.5(I-6)$ \\
ASQol (median, P25-P75) & $8(5.3-10.8)$ \\
PGA (median, P25-P75) & $44.5(21.3-60)$ \\
\hline A 5 (meviatons: AS anylosng &
\end{tabular}

Abbreviations: AS, ankylosing spondylitis; ASAS, Assessment of Spondylitis International Society; HLA-B27, human leukocyte antigen B27; P25-P75, percentile 25-75; BASDAI, Bath Ankylosing Spondylitis Disease Activity Index (scale 0-10); BASFI, Bath Ankylosing Spondylitis Functional Index (scale 0-10); BASMI, Bath Ankylosing Spondylitis Metrology Index (scale 0-10); ASDAS-CRP, Ankylosing Spondylitis Disease Activity Score-C reactive protein (scale 0-10); MASES, Maastricht Ankylosing Spondylitis Enthesitis Score (13 standardized points, range 0-13); ASQol, Ankylosing Spondylitis Quality of Life (scale 0-18); PGA, Patient Global Assessment (scale 0-100 mm).

Table 2 Cytokine concentrations $(\mathrm{pg} / \mathrm{mL})$ in cases and controls

\begin{tabular}{|c|c|c|c|}
\hline Cytokine & Patients $(n=32)$ & Controls $(n=32)$ & $p$-value \\
\hline IL- $12 \mathrm{p} 70^{\mathrm{a}}$ & $3.14(1.88-4.89)$ & $4.33(3.90-5.38)$ & $0.07 I^{c}$ \\
\hline IL-6 $6^{\mathrm{b}}$ & $4.80 \pm 1.40$ & $3.78 \pm 0.88$ & $0.003^{d}$ \\
\hline IL- $10^{\mathrm{b}}$ & $2.58 \pm 0.85$ & $2.13 \pm 0.53$ & $0.032^{\mathrm{d}}$ \\
\hline TNF- $\alpha^{a}$ & 5.01 (3.68-7.77) & $3.23(2.67-3.57)$ & $<0.00 I^{c}$ \\
\hline IL-I $I^{b}$ & $59.6 \pm 18.4$ & $60.3 \pm 12.8$ & $0.882^{d}$ \\
\hline $\mathrm{IL}-8^{\mathrm{a}}$ & $6.33(5.46-8.14)$ & $4.77(4.34-5.73)$ & $<0.00 I^{c}$ \\
\hline IL-23b & $267 \pm 81.2$ & $242 \pm 99.5$ & $0.252^{\mathrm{d}}$ \\
\hline IL- $17^{\mathrm{b}}$ & $6.20 \pm 0.88$ & $6.23 \pm 0.71$ & $0.902^{\mathrm{d}}$ \\
\hline
\end{tabular}

Notes: $n$ represents sample number. ${ }^{a}$ Median. ${ }^{b}$ Mean \pm standard deviation. 'Wilcoxon test. 'Student's $t$-test for matched samples.

There was a significant correlation of mean IL-6 concentration with the BASMI. No other correlations were observed.

Figure 1 illustrates the correlation of IL- 6 concentrations with the BASMI, showing that the higher the cytokine level, the higher was the BASMI.

We searched for associations of anti-TNF- $\alpha$ agent intake (present in 21 patients and absent in 11) and cytokine concentrations. There was no association of anti-TNF- $\alpha$ intake with the median or mean concentrations of any cytokine $(p>0.05$,
Mann-Whitney or Student's $t$-test adjusted for disease duration, BASMI, BASFI and ASQol by analysis of covariance).

We also looked for associations of anti-TNF- $\alpha$ intake with instruments of clinical evaluation. Anti-TNF- $\alpha$ intake was associated with an elevated BASMI ( $p=0.042$, MannWhitney test) and low quality of life as measured using the ASQol scale (0.009, Mann-Whitney test).

\section{Discussion}

Cytokine network seems to play an immunopathological role in AS. We herein compared cytokine concentrations of AS patients and age- and sex-matched controls, and correlated the cytokine profile with scores of disease activity and quality of life.

Out of the 32 AS patients, two were classified as having nr-axial SpA according to the ASAS criteria. Of note, both had symmetrical sacroiliitis. We decided to include these two patients considering a modern concept in which an nraxial SpA represents an early stage or an abortive form of AS. According to a recent study, no differences in clinical presentation, assessment of disease activity and response to anti-TNF- $\alpha$ agents were noticed between groups. ${ }^{11}$

Overall, our AS patients were predominantly middle-aged Caucasian males with long-standing disease. Preponderance of Caucasians was in accordance with the European surveys of AS. ${ }^{12}$ Only three of our patients $(9.4 \%)$ showed peripheral arthritis, while enthesitis was very frequent $(84.4 \%)$. A lower prevalence of enthesitis was seen in Latins (54\%) and Europeans (38\%) as compared to the results of our study. ${ }^{13}$ The frequency of HLA-B27 in the current study $(70 \%)$ was similar to a previous Brazilian description. ${ }^{14}$

The medians of BASDAI and BASFI in our patients were compatible with moderate disease activity despite treatment. A former Brazilian study reported a similar status of clinical activity. ${ }^{15}$ The current report originally evaluated BASMI, ASDAS-CRP and ASQol in a Brazilian survey of AS. While the BASDAI was elevated in $50 \%$ of cases, the ASDAS-CRP index was by far the most sensitive index, being altered in all cases. The ASQol and PGA data revealed not more than moderate quality of life. Owing to the high frequency of disease activity, two-third of our AS patients were being treated with anti-TNF- $\alpha$ agents.

In comparison to controls, our AS patients showed significantly high concentrations of most of the proinflammatory cytokines (IL-6, IL-8, TNF- $\alpha$ ). Elevated IL-6 levels were previously demonstrated in AS, with a positive association with CRP, platelet count and clinical parameters. ${ }^{16}$ Likewise, high levels of IL-8 were found in AS patients. ${ }^{17}$ Previous 
Table 3 Correlations of cytokine levels with instruments of clinical evaluation determined using the Spearman correlation

\begin{tabular}{llllllll}
\hline Cytokines & BASDAI & BASFI & BASMI & ASDAS-CRP & MASES & ASQol & PGA \\
\hline IL-12 & 0.057 & 0.045 & 0.167 & 0.268 & -0.05 I & -0.006 & -0.266 \\
IL-6 & -0.070 & 0.286 & $0.354^{*}$ & 0.099 & -0.097 & 0.229 & 0.012 \\
IL-I0 & -0.072 & -0.043 & -0.109 & -0.086 & -0.012 & 0.052 & -0.200 \\
TNF- $\alpha$ & 0.085 & 0.133 & 0.161 & 0.114 & -0.048 & -0.040 & 0.129 \\
IL-I & 0.08 I & 0.076 & 0.101 & 0.188 & 0.08 I & 0.223 & 0.142 \\
IL-8 & -0.087 & 0.075 & 0.159 & 0.046 & 0.052 & 0.319 & -0.008 \\
IL-23 & 0.042 & 0.172 & 0.146 & -0.101 & 0.229 & 0.27 I & -0.138 \\
IL-I7 & -0.057 & -0.350 & -0.080 & -0.030 & -0.210 & -0.177 & -0.165 \\
\hline
\end{tabular}

Notes: ${ }^{*} p=0.047$. Other correlations, $p>0.05$.

Abbreviations: BASDAI, Bath Ankylosing Spondylitis Disease Activity Index; BASFI, Bath Ankylosing Spondylitis Functional Index; BASMI, Bath Ankylosing Spondylitis Metrology Index; ASDAS-CRP, Ankylosing Spondylitis Disease Activity Score-C reactive protein; MASES, Maastricht Ankylosing Spondylitis Enthesitis Score; ASQol, Ankylosing Spondylitis Quality of Life; PGA, Patient Global Assessment.

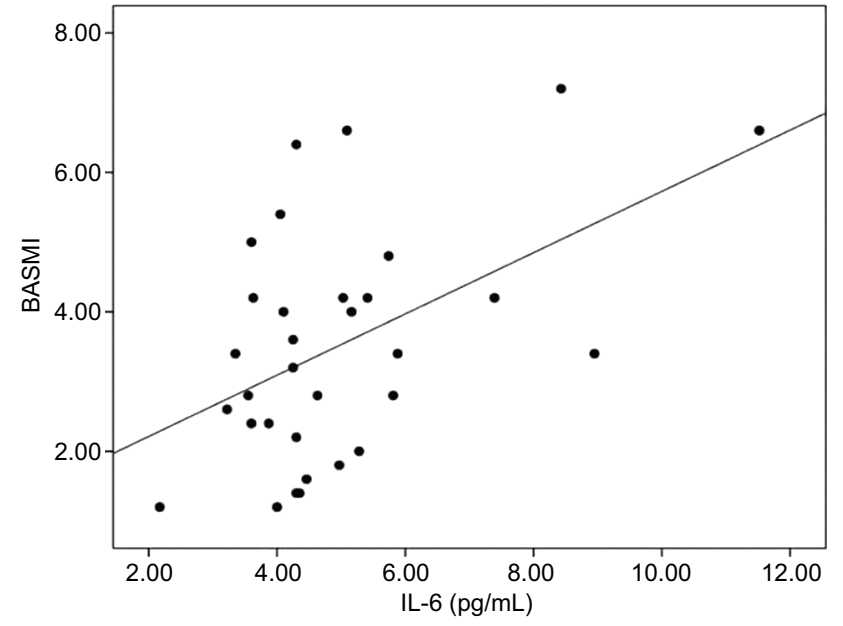

Figure I Correlation of IL- 6 concentrations with the BASMI $(r=0.354, p=0.047$, Spearman test).

Abbreviation: BASMI, Bath Ankylosing Spondylitis Metrology Index.

data associated IL-8 levels with the BASDAI and ASDAS, ${ }^{18}$ a finding not confirmed in the present study. Similar to our results, TNF- $\alpha$ levels were found to be high in AS patients, with no clear association with clinical indexes. ${ }^{19}$ We have no clear explanation why IL-8 and TNF- $\alpha$ concentrations failed to correlate with instruments of disease activity or quality of life. Further studies shall clarify the relationship of IL-8 and TNF- $\alpha$ levels with clinical indexes in AS.

Unexpectedly, concentrations of IL-1, IL-12, IL-23 and IL-17 did not differ between our AS patients and controls. In a 2012 study, differently, IL-12, IL-23 and IL-17, as well as IL-6, were all elevated in AS subjects. In the same report, an interesting correlation of IL-23 with the BASMI was found. ${ }^{20}$

Of note, levels of IL-10, an anti-inflammatory cytokine, were also high in our patients with AS. This hyperexpression of IL-10 might represent a suppressive response to inflammation. In 2011, increased serum levels of IL-10 were reported in Chinese patients with AS. ${ }^{21}$ As opposed, IL-10 levels did not differ between AS patients and controls in a Mexican study. ${ }^{22}$ As seen, the role of IL-10 in AS pathogenesis is a matter of controversy.

As to the correlations of cytokines with instruments of clinical evaluation, our only significant data was the link of IL-6 levels with the BASMI. This is an intriguing finding, once the BASMI selectively evaluates axial function. Yet in 1997, Falkenbach and Herold had demonstrated a relationship of IL-6 with three out of five non-standardized tests of axial mobility. ${ }^{23}$

Irrespective of high IL-6 levels in our AS patients, we found no association of this cytokine with composite scores (BASDAI, BASFI, ASDAS, MASES) and quality-of-life scores. The study of Bal et al accounted for high IL-6 in AS patients but, differently from our data, did not show correlation of this cytokine with the BASMI. ${ }^{24}$

As mentioned, only two previous studies searched for correlation of cytokines with the BASMI. ${ }^{20,24}$ Our study is probably the first correlating IL-6 with such a recognized index of axial mobility. If IL-6 is working as a biomarker of axial disease, this is a hypothesis to be further addressed. If confirmed, the impact in AS therapeutics would be a field to be explored. Nevertheless, a recent meta-analysis pointed to lower efficacy of tocilizumab, a blocker of IL-6 receptor, in comparison to infliximab and secukinumab in AS patients. ${ }^{25}$

Approximately two-third of our AS patients were on anti-TNF- $\alpha$ therapy. Anti-TNF- $\alpha$ users showed low quality of life and a high BASMI. As our patients had long-lasting disease, spinal deformities and hip involvement may have played an important role in axial dysfunction. We found no association of anti-TNF- $\alpha$ intake with the serum cytokine profile (TNF- $\alpha$ included). In another words, measurement of cytokines was not helpful to discriminate users and nonusers of anti-TNF- $\alpha$ agents.

Our study has limitations to be cited, mostly the crosssectional design (not allowing cause-effect statements) and the low casuistic. The fact that we have included only 
patients with classical AS restricted our sample, but allowed us a more selective interpretation of results. Current use of anti-inflammatory and immunosuppressive drugs may have altered the cytokine profile, comprising another study limitation.

\section{Conclusion}

We demonstrated that proinflammatory cytokines (IL-6, IL-8, TNF- $\alpha$ ) were upregulated in AS patients. The high IL-10 levels probably represented a suppressive feedback pathway. An intriguing and defined correlation of serum IL-6 with the BASMI was documented, suggesting a role for this cytokine in axial damage. Lastly, we showed that anti-TNF- $\alpha$ users had more axial activity and lower quality of life. Further research may elucidate the link of cytokines with instruments of clinical evaluation in AS.

\section{Disclosure}

The authors report no conflicts of interest in this work.

\section{References}

1. Dakwar E, Reddy J, Vale FL, Uribe JS. A review of the pathogenesis of ankylosing spondylitis. Neurosurg Focus. 2008;24(1):E2.

2. Smith JA. Update on ankylosing spondylitis: current concepts in pathogenesis. Curr Allergy Asthma Rep. 2015;15(1):489.

3. van der Linden S, Valkenburg HA, Cats A. Evaluation of diagnostic criteria for ankylosing spondylitis: a proposal for modification of the New York criteria. Arthritis Rheum. 1984;27(4):361-368.

4. Auleley GR, Dougados M, Baron G. Sample sizes estimated in clinical trials using either a composite index (ASAS response criteria) or single outcome variables in ankylosing spondylitis. Arthritis Rheum. 2002;46(6):1693-1694.

5. Garrett S, Jenkinson T, Kennedy LG, Whitelock H, Gaisford P, Calin A. A new approach to defining disease status in ankylosing spondylitis: the Bath Ankylosing Spondylitis Disease Activity Index. J Rheumatol. 1994; 21(12):2286-2291

6. Calin A, Garrett S, Whitelock H, et al. A new approach to defining functional ability in ankylosing spondylitis: the development of the Bath Ankylosing Spondylitis Functional Index. J Rheumatol. 1994; 21(12):2281-2285.

7. Jenkinson TR, Mallorie PA, Whitelock HC, Kennedy LG, Garrett SL, Calin A. Defining spinal mobility in ankylosing spondylitis (AS). The Bath AS Metrology Index. J Rheumatol. 1994;21(9):1694-1698.

8. Lukas C, Landewé R, Sieper J, et al; Assessment of SpondyloArthritis international Society. Development of an ASAS-endorsed disease activity score (ASDAS) in patients with ankylosing spondylitis. Ann Rheum Dis. 2009;68(1):18-24.
9. Heuft-Dorenbosch L, Spoorenberg A, van Tubergen A, et al. Assessment of enthesitis in ankylosing spondylitis. Ann Rheum Dis. 2003; 62(2):127-132.

10. Doward LC, Spoorenberg A, Cook SA, et al. Development of the ASQol: a quality of life instrument specific to ankylosing spondylitis. Ann Rheum Dis. 2003;62(1):20-26.

11. Baraliakos X, Braun J. Non-radiographic axial spondyloarthritis and ankylosing spondylitis: what are the similarities and differences? RMD Open. 2015;1 (Suppl 1):e00053.

12. Stolwijk C, Boonen A, van Tubergen A, Reveille JD. Epidemiology of spondyloarthritis. Rheum Dis Clin North Am. 2012;38(3):441-476.

13. Benegas M, Muñoz-Gomariz E, Font P, et al; RESPONDIA group; ASPECT study group; REGISPONSER study group. Comparison of the clinical expression of patients with ankylosing spondylitis from Europe and Latin America. J Rheumatol. 2012;39(12):2315-2320.

14. Sampaio-Barros PD. Epidemiology of spondyloarthritis in Brazil. Am J Med Sci. 2011;341(4):287-288.

15. Gallinaro AL, Ventura C, Sampaio Barros PD, Gonçalves CR. Spondyloarthritis: analysis of a Brazilian series compared with a large IberoAmerican registry (RESPONDIA group). Rev Bras Reumatol. 2010; 50(5):581-589.

16. Gratacós J, Collado A, Filella X, et al. Serum cytokines (IL-6, TNFalpha, IL-1 beta and IFN-gamma) in ankylosing spondylitis: a close correlation between serum IL-6 and disease activity and severity. Br J Rheumatol. 1994;33(10):927-931.

17. Azuz-Lieberman N, Markel G, Mizrahi S, et al. The involvement of NK cells in ankylosing spondylitis. Int Immunol. 2005;17(7):837-845.

18. Azevedo VF, Faria-Neto JR, Stinghen A, et al. IL-8 but not other biomarkers of endothelial damage is associated with disease activity in patients with ankylosing spondylitis without treatment with anti-TNF agents. Rheumatol Int. 2013;33(7):1779-1783.

19. Wang J, Zhao Q, Wang G, et al. Circulating levels of Th1 and Th2 chemokines in patients with ankylosing spondylitis. Cytokine. 2016;81:10-14.

20. Taylan A, Sari I, Kozaci DL, et al. Evaluation of the T helper 17 axis in ankylosing spondylitis. Rheumatol Int. 2012;32(8):2511-2515.

21. Lv C, Wang Y, Wang J, Zhang H, Xu H, Zhang D. Association of Interleukin-10 gene polymorphisms with ankylosing spondylitis. Clin Invest Med. 2011;34(6):E370.

22. Vazquez-Del Mercado M, Garcia-Gonzalez A, Muñoz-Valle JF, et al. Interleukin 1beta (IL-1beta), IL-10, tumor necrosis factor-alpha, and cellular proliferation index in peripheral blood mononuclear cells in patients with ankylosing spondylitis. J Rheumatol. 2002;29(3): 522-526.

23. Falkenbach A, Herold M. In ankylosing spondylitis serum interleukin-6 correlates with the degree of mobility restriction, but not with short-term changes in the variables for mobility. Rheumatol Int. 1998; 18(3):103-106.

24. Bal A, Unlu E, Bahar G, Aydog E, Eksioglu E, Yorgancioglu R. Comparison of serum IL-1 beta, sIL-2R, IL-6, and TNF-alpha levels with disease activity parameters in ankylosing spondylitis. Clin Rheumatol. 2007;26(2):211-215.

25. Chen C, Zhang X, Xiao L, Zhang X, Ma X. Comparative effectiveness of biologic therapy regimens for ankylosing spondylitis: a systematic review and a network meta-analysis. Medicine (Baltimore). 2016; v95(11):e3060.
Open Access Rheumatology: Research and Reviews

\section{Publish your work in this journal}

Open Access Rheumatology: Research and Reviews is an international, peerreviewed, open access journal publishing original research, reports, editorials, reviews and commentaries on all aspects of clinical and experimental rheumatology in the clinic and laboratory including the following topics: Pathology, pathophysiology of rheumatological diseases; Investigation, treatment and management of rheumatological diseases; Clinical trials and novel pharmacologi$\mathrm{cal}$ approaches for the treatment of rheumatological disorders. The manuscript management system is completely online and includes a very quick and fair peer-review system, which is all easy to use. Visit http://www.dovepress.com/ testimonials.php to read real quotes from published authors. 